\title{
Nanotechnology in Battle against CoViD-19: The Prevention, Diagnosis, and Treatment
}

\author{
Meet A. Moradiya ${ }^{1}$, Pradeep Kumar Khiriya ${ }^{1}$, Purnima Swarup Khare ${ }^{1}$, J. H. Markna ${ }^{2, *}$ \\ 1 School of Nanotechnology, Rajiv Gandhi Proudyogiki Vishwavidyalaya, Bhopal, Madhya Pradesh, India \\ 2 Department of Nanotechnology, V.V.P. Engineering College, Rajkot, Gujarat, India \\ * Correspondence: jaysukh28@gmail.com;
}

Scopus Author ID 10439287000

Received: 25.01.2021; Revised: 30.03.2021; Accepted: 5.04.2021; Published: 7.05.2021

\begin{abstract}
People worldwide are experiencing the most dangerous situation concerning the novel severe acute respiratory syndrome known as coronavirus-2 (SARS-CoV-2), commonly referred to as the novel coronavirus disease-2019 (CoViD-19). Since late December 2019, an epidemic of coronavirus disease 2019 (CoViD-19) occurred in Wuhan, China, and rapidly spread to almost all parts of China. With the growing global burden of the CoViD-19 pandemic, scientists, researchers, and healthcare-related organizations constantly work for a viable vaccine or therapeutics, scalable detection methods, personal protection devices, and novel effective medical solutions. Nanotechnology has recently considerably addressed the many clinical and public healthcare issues that have emerged from the CoViD-19 pandemic. The main focus of this current review article is to explore the possibility and potential of nanotechnology to combat this global pandemic and ongoing mitigation techniques and strategies. Furthermore, novel nanotechnology-based products are currently being developed for the prevention, diagnostic, treatment of CoViD-19, which various researchers or healthcare organizations invent.
\end{abstract}

Keywords: coronavirus; CoViD-19; SARS-CoV-2; nanotechnology; prevention; diagnosis; treatment.

(C) 2021 by the authors. This article is an open-access article distributed under the terms and conditions of the Creative Commons Attribution (CC BY) license (https://creativecommons.org/licenses/by/4.0/).

\section{Introduction}

Coronavirus disease 2019 (CoViD-19) is a single-stranded (ss) RNA genome that was newly identified in Wuhan, China, in December 2019 and quickly spread across China and around the world [1,2]. Since, then the disease has spread to 213 countries and regions, with more than 4.8 million confirmed cases and more than 320,188 deaths as of May 18, 2020 [3]. On January 30, 2020, CoViD-19 patients presented (fever, cough, and difficulty in breath) and other symptoms such as pneumonia, fatigue, and diarrhea [4]. In the past 18 years, several viral infectious diseases have been reported, including severe acute respiratory syndrome coronavirus (SARS-CoV) in 2002-2003 and H1N1 influenza in 2009 [5, 6]. In 2012, middle east respiratory syndrome coronavirus (MERS-CoV) was reported for the first time in the region of Saudi Arabia [7, 8]. Since the spread of this novel virus worldwide, the World Health Organization (WHO) has stated a 6th public health emergency of international concern for coronavirus disease [9]. As compared to SARS-CoV, the CoViD-19 has shown enhanced levels of pandemic and transmission risk, as the effective estimated reproduction number $\left(\mathrm{R}_{0}\right)$ of CoViD-19 or SARS-CoV-2 (2-3.5) was found to be more than the earlier reported effective $\mathrm{R}_{0}$ of SARS-CoV (1.77) during the early period [10]. Also, the low $\mathrm{R}_{0}$ has been reported for 
MERS-CoV, which is 0.7. The results from various laboratories have also revealed that CoViD-19 exhibits pathogenesis and behavioral conditions similar to those of beta-CoV genera recognized in bats located in a group of SARS or SARS-like CoV [11].

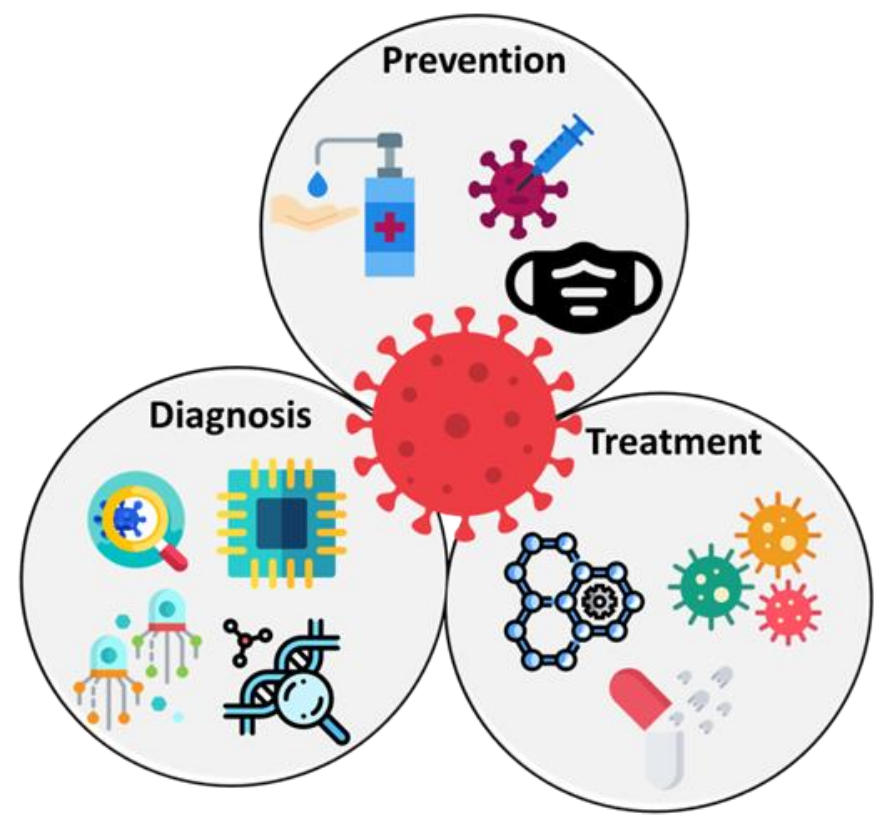

Figure 1. Illustration of nanotechnology-based prevention, diagnosis, and treatment for CoViD-19.

The SARS-CoV-2 fits the largest family of the RNA viruses, and its RNA genome ranges from $\sim 125$ nanometers or 0.125 microns in size. It is a positive single-stranded (++ss) enveloped RNA virus with a 5'-cap structure and 3'-poly-A tail [12]. The newly identified virus has four important structural proteins, such as (E) the envelope protein, (M) the membrane protein, $(\mathrm{S})$ the spike protein, and $(\mathrm{N})$ the nucleocapsid protein, which is necessary to normalize the function and viral structure [13]. Among them, $\mathrm{N}$ and $\mathrm{S}$ are the most important. The nucleocapsid protein $(\mathrm{N})$ helps to develop the capsid and all of the viral structure appropriately, and the Spike (S) protein of SARS-CoV-2 and SARS-CoV enter human alveolar epithelial cells by connecting to the angiotensin-converting-2 receptor [14]. It undergoes structural changes to merge with the host, allowing viral genes to enter the host cell. At present, there are no vaccines or antibodies, or drugs available for CoViD-19. However, a research effort is currently underway to develop a vaccine or antibodies against attenuation of the coronavirus, and some may be available in a short time [15]. As one of the game-changers of the past many years, nanotechnology holds great promise for bringing revolutionary solutions to a wide range of issues regarding the monitoring, testing, and treatment of SARS-CoV-2 or CoViD -19, in which nanotechnologists undoubtedly play a major role [16, 17]. This article summarizes the different nanotechnology products available to fight against the coronavirus developed by researchers, scientists, and healthcare organizations. Figure 1 also illustrated the nanotechnology-based prevention, diagnosis, and treatment for CoViD-19.

\section{Nanotechnology-based Prevention Strategy against CoViD-19}

Nanotechnology likely holds huge potential in the prevention of coronavirus. Nanotechnology could help the fight against covid-19 through different prevention strategies, such as developing nano-based vaccination to protect against infectious agents, the design of protective equipment to enhance the safety of healthcare workers, and the development of nanotech-based effective disinfectant and surface coating technology. 


\subsection{Nanotechnology-based vaccine candidates.}

Nanotechnology-based vaccine candidates tonix pharmaceuticals and their research collaboration have developed three vaccine candidates, termed TNX-1810, TNX-1820, and TNX-1830 based on horsepox virus vaccine (Virosomesbased vaccine) that designed to express Spike Protein (S) from the virus that causes CoViD-19 [18]. It is believed that nanotechnology is used to design a nanometer-scale viral vector to deliver vaccine agents to protect against infectious agents. [19]. CanSino Biological Inc., Beijing Institute of Biotechnology, CanSino Biological Inc., Beijing Institute of Biotechnology, China has developed a genetically modified vaccine candidate based on type 5 adenovirus ( $\mathrm{Ad} 5-\mathrm{nCoV}$ ) to expel type $\mathrm{S}$ protein, which is proposed to prevent the Coronavirus disease. In addition, they also designed a nanometer-scale viral vector to deliver vaccine agents to the human cell [20]. Jenssen Pharmaceutical has designed a viral vector based on nanotechnology to deliver a vaccination agent. Jenssen's vaccination program will use Janssen AdVac ${ }^{\circledR}$ and PER $®$ technologies to invent recombinant vaccines against life-threatening infectious diseases (eg CoViD-19) [21]. The company name Ufovax has successfully designed self-assembled protein nanoparticles based on a vaccine technology that works against CoViD-19. The nanoparticle vaccine might stimulate the human immune structure to quickly generate antibodies to neutralize the SARS-CoV-2 protein [22]. The University of Queensland has synthesized the self-formed polypeptide to shape an artificial enclosed virus fusion protein complex. This nanotechnology-based vaccine has been developed to lock the $\mathrm{S}$ protein in a form that allows the immune system to recognize and then neutralize the virus [23]. Novavax trained the CoViD-19 vaccine candidate using recombinant F proteins that are self-assembled in nanoparticle technology to create antigens obtained from the advanced protein of the coronavirus. Novavax plans to use its patented adjuvant Matrix-M TM with its SARS-CoV-2 vaccine candidate to improve immune responses [24]. Moderma Inc. created the mV-RNA-1273 vaccine agent technology against CoViD-19. In this technology, the stretching of the RNA necessary to prepare the vaccine is first synthesized using lipid nanoparticles (LNP) [25]. Arcturus has developed the STARR ${ }^{\mathrm{TM}}$ technological platform, which combines self-replicating RNA with a non-viral delivery system of advanced nanoparticles to produce proteins inside the human body. Due to the excellent immune response and sustained protein expression, Arcturus' STARR ${ }^{\text {TM }}$ Technology is expected to build a vaccine response at much lower doses than conventional mRNA vaccines [26]. This could lead to the capability to treat many more people with a single batch of manufactured products, thereby significantly increasing efficacy and reducing the time required to produce enough amounts of vaccine for mass populations [27]. Entos Pharmaceuticals uses a neutral Liposome formulation with the high efficiency of the fusogenic protein-based delivery technology that uses a facile fusion mechanism to transfer its genetic payload directly inside the cells. This formulation will create long-standing immunity against infection by viruses such as CoViD-19 [28]. At the University of Waterloo, the Mediphage Research Group has created a nasal vaccine to encourage an immune response in the cavity of the nasal and target tissues of the lower respiratory tract. In addition, they use VLPs to mimic the natural structure of viruses [29]. GeoVax, Inc. has created the self-building of the virus-like particle in the cells whose platform is to build vaccine candidates using genetic sequences from the current CoViD-2019 pandemic [30]. Medicago invented a vaccine based on virus-like nanoparticles derived from plants, permitting them to be recognized by the immune system. The Medicago and Infectious Disease Research Centre, Laval University, uses this invention to develop antibodies against CoViD-19 [31]. All these 
nanotechnology-based vaccine candidates are in the preclinical evaluation or the regulatory stage.

\subsection{Nanomaterials-based respiratory masks and air filtration systems.}

The Ahmedabad Textile Industry Research Association (ATIRA) and Defence Research and Development Organization (DRDO) have invented 5-layered N-99 masks with the use of a nanoweb filter with advanced two layers of nano-mesh [32]. One of the company's name LIGC has recently manufactured a laser-induced graphene-based reusable respirator face mask that can conduct e- charge to kill the trapped pathogens in the mask's filter effective in eliminating $99 \%$ of particles [33]. Directa Plus PLC has shown that the graphene material can be used to produce masks, gloves, and gowns for the CoViD19 pandemic due to its non-toxic and bacteriostatic properties. Promethean Particles Ltd has collaborated with textile companies to synthesize antimicrobial copper nanoparticles based on non-woven fabrics to resistant against CoViD-19 [34]. Czech nanofiber technology has invented innovative masks that have the capacity to isolating and killing viruses. Their product name ReSpimask provides efficient protection of the human respiratory tract against air pollution, viruses, and bacteria, as it captures $99.9 \%$ of airborne particles. This technology uses the combination of nanofiber and copper nanoparticles $(\mathrm{CuO})$ to combat the CoViD-19 [35]. Integricote Inc. and the University of Houston have designed the hydrophobic coating manufactured almost a decade ago to increase the capability of surgical masks to protect against transmission of the virus, which is now using to determine a way to offer more protection against SARS and CoViD-19 [36]. MVX Prime Ltd. fabricates a self-cleaning sanitizing surgical nano mask that is confirmed to kill $99.9 \%$ of all pathogens that come into contact. The Nano Mask has a size ranging between 1-2 $\mathrm{mm}$ that is powerful towards coronavirus and enormous value in preventing infection and disease reduction [37]. Anson Nano-Biotechnology has designed safe, reusable masks that include the nanosilver fabric lining the masks, which can help protect users from microorganisms so that the NPs constantly release ions capable of killing viruses and bacteria [38]. $\mathrm{XTiO}_{2}$ presents XTITM Active Nano-based face mask, which can deliver effective protection against germs, bacteria, and viruses transmitted by air. The outer layer of $\mathrm{TiO}_{2}$ can be refreshed by direct exposure to sunlight (UV) to kill the accumulated germs [39]. The company copper3D produces a facial mask that comprises 3 layers of non-woven polypropylene infused with 5\% copper oxide nanoparticles, having high antimicrobial, antiviral, and antibacterial properties [40]. The products manufactured by Metamasks are made from natural and affordable nanofibers using an exclusive coconut nanocarbon filter, which inhibits up to $99.99 \%$ of toxic air pollution from entering the body [41]. The researchers at the Queensland University of Technology (QUT) have prepared an incredibly breathable cellulosebased nanofiber that is capable of removing virus-size nanoparticles [42]. The company name Mack Antonoff HVAC and Turn-Key Environmental Consultants sells has designed a nanotechnology-based air filtration system that can capture $99.5 \%$ of pathogens in its network of nanofibers [33]. The University of South Florida's newly designed air purification device based on photochemical oxidation technology called Molekule, which was used to test against coronavirus in March 2020, can effectively destroy air pollutants, including bacteria viruses, and mold spores [43]. 


\subsection{Nanomaterials-based commercial disinfectants technology.}

Nano4life Europe has created a surface sanitizer capable of instantly killing the surface pathogens such as viruses, bacteria, and fungus. Thus, the Nano4-Hygienenlife does not kill cells by absorbing the wall of pathogens; it acts from the inside. It is a physical effect by which the cells are instantly killed once they met the external surface [44]. FN Nano Inc., a company, has developed a novel $\mathrm{TiO}_{2}$-based photocatalytic nanocoating, which can break down and eliminate the pathogens such as viruses, bacteria, and mold on its surface exposed to light [45]. The Indian start-up We innovate Biosolutions named has developed non-alcoholic colloidal silver nanoparticles, which can disinfect hands and surface where the novel coronavirus may survive from several hours to several days [46]. Hong Kong University of Science and Technology (HKUST) has developed a disinfectant solution that can protect surfaces for up to 90 days and kill the coronavirus and other microorganisms [47]. At Marmo Service, which deals with nanotechnology, the name of the company has developed transparent disinfectant solutions based on nanotechnology to eliminate the coronavirus. This innovation is composed of $\mathrm{TiO}_{2}$ and $\mathrm{Ag}$ nanoparticles, allowing the surface to self-sterilize for up to two years [48]. The other nanotechnology-based disinfectant companies such as Dongyang Nanotech Co, M9 Ltd., Shepros Sds bhd, Nanogist Co., Ltd, Lion Corporation, Silver MSM, and Claypia Co., Ltd, are produced soaps incorporated into the nanosilver, having antiviral and antibacterial properties.

\section{Nanomaterials Based Diagnosis for CoViD-19}

Various organizations are already working on designing a highly sensitive and selective nanosensor for rapid detection of infection or immunological responses. The companies Mologic Ltd UK and SureScreen Diagnostics Ltd UK have developed test strips based on gold nanoparticles to detect coronavirus, IgG, and IgM biomarkers up to $97.8 \%$ and $99.65 \%$ of accuracy, respectively, which are released on contact with antibodies implanted in the strip [49]. This approach is much like that of the pregnancy test. One of the proprietary nanotechnology firms Sona Nanotech has developed the rapid screening test for the CoViD19. They developed a fast lateral-flow test for the CoViD-19 patients. The test is expected to produce outcomes in 5-15 minutes and is predictable to price less than $\$ 50$. [50]. The Department of Clinical and Molecular Medicine, Norway, and the Department of Chemical Engineering, in collaboration with St. Olavs Hospital, is building on this affinity to develop a new method using nanoparticles coated with silica $\left(\mathrm{Si}-\mathrm{Fe}_{2} \mathrm{O}_{3}\right)$ [51]. The solution incorporates materials that open the virus so that the material can be extracted. The virus RNA in the solution is attracted to the magnetic NPs coated with silica. The next phase is to use a magnet to extract the RNA-covered particles from the solution. It can then recognize the genetic code from the RNA and match it to the coronavirus [51].

\section{Treatment of CoViD-19 Using Nanotechnology}

The various institutions are developing new drugs with enhanced activity, decreased toxicity, and sustained release to combat the coronavirus. Northwestern University (NU) and the Massachusetts Institute of Technology (MIT) have developed a novel nanostructure-based engineered peptide that could potentially eliminate and deactivate the virus as well as prevent its infection of human cells [52]. They have been working on millions of peptides in a nanostructure that becomes the transporter of valuable drugs. The drug's relatable chemistry 
and the carrier allow researchers to construct nanostructures that defend the peptide drug as it travels through the body before it kills the coronavirus [53]. Bioavanta LLC and Bosti Trading LTD have designed biocompatible chitosan-based nanoparticles that strongly stick to epithelial tissue of the lung and ensure prolonged release [33]. Extensive preclinical tests, carried out by the academic partners of Bioavanta-Bosti, have shown that the Novochizol is a safe and effective nano-drug; in particular, it is an ideal intrapulmonary administration system [54]. All these nanotechnology-based treatments are in the preclinical evaluation phase or the regulatory stage.

\section{Conclusions}

The CoViD-19 pandemic is spreading worldwide at an alarming rate. It has caused more infections and deaths than SARS or MERS. Nanotechnology and nanomaterials can significantly address the various clinical and public health challenges from the CoViD-19 pandemic. In this review, we analyze and examine the nanotechnology-based products that are currently being developed and deployed for the diagnosis, prevention, and treatment of CoViD19. Nanotechnology and nanomaterials have enough potential and possibilities to contribute to this global pandemic and ongoing combat strategy.

\section{Funding}

This research received no external funding.

\section{Acknowledgments}

This research has no acknowledgment.

\section{Conflicts of Interest}

The authors declare no conflict of interest.

\section{References}

1. Lai, C.C.; Shih, T.P.; Ko, W.C.; Tang, H.J.; Hsueh, P.R. Severe acute respiratory syndrome coronavirus 2 (SARS-CoV-2) and coronavirus disease-2019 (COVID-19): The epidemic and the challenges. Int J Antimicrob Agents. 2020, 55, https://doi.org/10.1016/j.ijantimicag.2020.105924.

2. Ramphul, K; Mejias, S.G. Coronavirus Disease: A Review of a New Threat to Public Health. Cureus 2020, 19, https://doi.org/10.7759/cureus.7276.

3. https://www.worldometers.info/coronavirus/?utm_campaign=homeAdUOA?Si

4. Vellingiri, B.; Jayaramayya, K.; Iyer, M.; Narayanasamy, A.; Govindasamy, V.; Giridharan, B.; Ganesan, S.; Venugopal, A.; Venkatesan, D.; Ganesan, H.; Rajagopalan, K.; Rahman, P.K.S.M.; Cho, S.-G.; Kumar, N.S.; Subramaniam, M.D. COVID-19: A promising cure for the global panic. Science of The Total Environment 2020, 725, https://doi.org/10.1016/j.scitotenv.2020.138277.

5. Yang, Y; Islam, M.S; Wang, J.; Li, Y.; Chen, X. Traditional Chinese Medicine in theTreatment of Patients Infected with 2019-New Coronavirus (SARS-CoV-2): A Review and Perspective. Int J Biol Sci. 2020, 16, 1708-1717, https://doi.org/10.7150/ijbs.45538.

6. Xie, M.; Chen, Q. Insight into 2019 novel coronavirus -an updated intrim review and lessons from SARSCoV and MERS-CoV. Int J Infect Dis. 2020, 94, 119-124, https://doi.org/10.1016/j.ijid.2020.03.071.

7. Xu, J.; Zhao, S.; Teng, T.; Abdalla, A.E.; Zhu, W.; Xie, L.; Wang, Y.; Guo, X. Systematic Comparison of Two Animal-to-Human Transmitted Human Coronaviruses: SARS-CoV-2 and SARS-CoV. Viruses 2020, 12, https://doi.org/10.3390/v12020244.

8. Petrosillo, N.; Viceconte, G.; Ergonul, O.; Ippolito, G.; Petersen, E. COVID-19, SARS and MERS: are they closely related? Clinical Microbiology and Infection 2020, 26, 729-734, https://doi.org/10.1016/j.cmi.2020.03.026. 
9. Chang, L.; Yan, Y.; Wang, L. Coronavirus Disease 2019: Coronaviruses and Blood Safety. Transfus Med Rev. 2020, 34, 75-80, https://doi.org/10.1016/j.tmrv.2020.02.003.

10. Yang, Y.; Islam, M.S.; Wang, J.; Li, Y.; Chen, X. Traditional Chinese Medicine in theTreatment of Patients Infected with 2019-New Coronavirus (SARS-CoV-2): A Review and Perspective. Int J Biol Sci. 2020, 16, 1708-1717, https://doi.org/10.7150/ijbs.45538.

11. Fani, M.; Teimoori, A.; Ghafari, S. Comparison of the COVID-2019 (SARS-CoV-2) pathogenesis with SARS-CoV and MERS-CoV infections. Future Virolology 2020, https://doi.org/10.2217/fvl-2020-0050.

12. Zhai, P.; Ding, Y.; Wu, X.; Long, J.; Zhong, Y.; Li, Y. The epidemiology, diagnosis and treatment of COVID-19. International Journal of Antimicrobial Agents 2020, 55, https://doi.org/10.1016/j.ijantimicag.2020.105955.

13. Udugama, B.; Kadhiresan, P.; Kozlowski, H.N.; Malekjahani, A.; Osborne, M.; Li, V.Y.C.; Chen, H.; Mubareka, S.; Gubbay, J.B.; Chan, W.C.W. Diagnosing COVID-19: The Disease and Tools for Detection. ACS Nano 2020, 14, 3822-3835, https://doi.org/10.1021/acsnano.0c02624.

14. Zhou, P.; Yang, X.-L.; Wang, X.-G.; Hu, B.; Zhang, L.; Zhang, W.; Si, H.-R.; Zhu, Y.; Li, B.; Huang, C.L.; Chen, H.-D.; Chen, J.; Luo, Y.; Guo, H.; Jiang, R.-D.; Liu, M.-Q.; Chen, Y.; Shen, X.-R.; Wang, X.; Zheng, X.-S.; Zhao, K.; Chen, Q.-J.; Deng, F.; Liu, L.-L.; Yan, B.; Zhan, F.-X.; Wang, Y.-Y.; Xiao, G.-F.; Shi, Z.-L. A pneumonia outbreak associated with a new coronavirus of probable bat origin. Nature 2020, 579, 270-273,https://doi.org/10.1038/s41586-020-2012-7.

15. Dhama, K.; Sharun, K.; Tiwari, R.; Dadar, M.; Malik, Y.S.; Singh, K.P.; Chaicumpa, W. COVID-19, an emerging coronavirus infection: advances and prospects in designing and developing vaccines, immunotherapeutics, and therapeutics. Human Vaccines \& Immunotherapeutics 2020, 16, 1232-1238, https://doi.org/10.1080/21645515.2020.1735227.

16. Sivasankarapillai, V.S.; Pillai, A.M.; Rahdar, A.; Sobha, A.P.; Das, S.S.; Mitropoulos, A.C.; Mokarrar, M.H.; Kyzas, G.Z. On Facing the SARS-CoV-2 (COVID-19) with Combination of Nanomaterials and Medicine: Possible Strategies and First Challenges. Nanomaterials 2020, 10, https://doi.org/10.3390/nano10050852.

17. Nikaeen, G.; Abbaszadeh, S.; Yousefinejad, S. Application of nanomaterials in treatment, anti-infection and detection of coronaviruses. Nanomedicine 2020, 15, 1501-1512, https://doi.org/10.2217/nnm-2020-0117.

18. Globe Newswire. Tonix Pharmaceuticals Enters into Research Collaboration and Exclusive License Agreement with University of Alberta to Develop Novel Horsepox-Based Vaccines, TNX-1810, TNX-1820 and TNX1830, for the Prevention of COVID-19. May 2020, Retrived from https://ir.tonixpharma.com/pressreleases/detail/1198/tonix-pharmaceuticals-enters-into-research-collaboration.

19. Singh, L.; Kruger, H.G.; Maguire, G.E.M.; Govender, T.; Parboosing, R. The role of nanotechnology in the treatment of viral infections. Therapeutic Advances in Infectious Disease 2017, 4(4): 105-131, $10.1177 / 2049936117713593$

20. TSN. CanSino Biologics' Ad5-nCoV the First COVID-19 Vaccine to Phase II Clinical Trials. April 2020, Retrived from https://trialsitenews.com/cansino-biologics-ad5-ncov-the-first-covid-19-vaccine-to-phase-iiclinical-trials/

21. Funk, C.D.; Laferrière, C.; Ardakani, A. A Snapshot of the Global Race for Vaccines Targeting SARS-CoV2 and the COVID-19 Pandemic. Frontiers in Pharmacology 2020, https://doi.org/10.3389/fphar.2020.00937.

22. Wilmington. Ufovax successfully extended its Nanoparticle vaccine technology to SARS-CoV-2. March 2020. Retrived from https://www.businesswire.com/news/home/20200323005751/en/Ufovax-successfullyextended-its-Nanoparticle-vaccine-technology-to-SARS-CoV-2

23. Machhi, J.; Shahjin, F.; Das, S.; Patel, M.; Abdelmoaty, M.; Cohen, J.D,; Singh, P.A.; Baldi, A.; Bajwa, N.; Kumar, R.; Vora, L.K.; Patel, T.; Oleynikov, MD.; Soni, D.; Yeapuri, P.; Mukadam, I.; Chakraborty, R.; Saksena, C.G.; Herskovitz, J.; Hasan, M.; Oupicky, D.; Das, S.; Donnelly, R.F.; Hettie, K.S,; Chang, L.; Gendelman, H.E,; Kevadiyaa, B.D. Nanocarrier Vaccines for SARS-CoV-2. Advance Drug Delivery Review 2021, 10.1016/j.addr.2021.01.002

24. Chung, Y.H.; Beiss, V.; Fiering, S.N.; Steinmetz, N.F. COVID-19 Vaccine Frontrunners and Their Nanotechnology Design. ACS Nano. 2020, 10.1021/acsnano.0c07197

25. Blakney, A.K.; Ip, S.; Geall, A.J. An Update on Self-Amplifying mRNA Vaccine Development. Vaccines 2021, 9, 97, https:// doi.org/10.3390/vaccines9020097

26. Shin, M. D.; Shukla, S.; Chung, Y. H.; Beiss, V.; Chan, S. K.; Ortega-Rivera, O. A,; Wirth, D. A.; Chen, A.; Sack, M.; Pokorski, J. K.; Steinmetz, N. F. COVID-19 vaccine development and a potential nanomaterial path forward. Nature Nanotechnology 2020, 15, 646-655, 10.1038/s41565-020-0737-y.

27. Amanat, F.; Krammer, F. SARS-CoV-2 Vaccines: Status Report. Immunity 2020, 52, 583-589, https://doi.org/10.1016/j.immuni.2020.03.007.

28. Junker, A. COVID-19: Edmonton company developing DNA-based vaccine, 2020 Retrived from https://edmontonjournal.com/news/local-news/covid-19-edmonton-company-developing-dna-basedvaccine

29. Jentsch, P.; Anand, M.; Bauch, C. T. Prioritising COVID-19 vaccination in changing social and epidemiological landscapes 2020, https://doi.org/10.1101/2020.09.25.20201889 
30. Campbell, M.; COVID-19 Vaccine Development: An Interview With GeoVax. 2020, Retrived from https://www.technologynetworks.com/biopharma/blog/covid-19-vaccine-development-an-interview-withgeovax-332972https://www.ulaval.ca/en/about-us/media-centre/press-releases/press-releases-2020/21million-better-understand-and-combat-covid-19.

31. Textile body develops high-quality cloth to make 'N-99' masks, 2020, Retrived from https://www.deccanherald.com/business/textile-body-develops-high-quality-cloth-to-make-n-99-masks827581.html

32. Chua, M. H.; Cheng, W.; Goh, S. S.; Kong, J.; Li, B.; Lim, B.; Mao, L.; Wang, S.; Xue, K.; Yang, L.; Ye, E.; Zhang, K.; Cheong, W.C.D.; Tan, B. H.; Li, Z.; Tan, B.; Loh, X. J. Face Masks in the New COVID-19 Normal: Materials, Testing, and Perspectives. Research (Wash D C), 2020, 10.34133/2020/7286735.

33. Chaudhary, V.; Royal, A.; Chavali M.; Yadav, S. K. Advancements in research and development to combat COVID-19 using nanotechnology. Nanotechnology for Environmental Engineering, 2020,8(6), 10.1007/s41204-021-00102-7

34. Lea, R. Graphene-Based Masks Launched to Combat COVID-19, 2020, Retrived from https://www.azonano.com/news.aspx?newsID=37431

35. Parekh, A.; Chitguppi, R. Nanotechnology: A Forerunner In The Fight Against Covid19. 2020, 10.13140/RG.2.2.32957.90083

36. Kever, J. Nanotech Filter Coating Offers Promise Against COVID-19, 2020, Retrived from https://www.uh.edu/news-events/stories/2020/september-2020/09292020-curran-covid-filter.php

37. Cavalcanti, I. D. L.; Nogueira, M. C. Pharmaceutical nanotechnology: which products are been designed against COVID-19? J Nanopart Res. 2020, 22, 9, 276, 10.1007/s11051-020-05010-6.

38. Chua, M. H.; Cheng, W.; Goh, S. S.; Kong, J.; Li, B.; Lim, J.; Mao, J.; Wang, S.; Xue, K.; Yang, L.; Ye, E.; Zhang, K. Face Masks in the New COVID-19 Normal: Materials, Testing, and Perspectives. AAAS Research 2020, https://doi.org/10.34133/2020/7286735.

39. XTIO2 INC. XTIO2 INC. Presents XTI 360 Global Anti-Germ System on Earth Day. 2011, Retrieved from https://www.prnewswire.com/news-releases/xtio2-inc-presents-xti-360-global-anti-germ-system-on-earthday-120359654.html.

40. Román, L. E.; Gomez, E. D.; Solís, J. L.; Gómez, M. M. Antibacterial Cotton Fabric Functionalized with Copper Oxide Nanoparticles. Molecules. 2020, 25, 24, 5802, 10.3390/molecules25245802

41. Metamasks Pushes for Sustainable and Eco-Friendly Face Masks for Five Years and Counting, 2020, Retrived from https://www.wfmj.com/story/42979284/metamasks-pushes-for-sustainable-and-eco-friendlyface-masks-for-five-years-and-counting.

42. New filter material blocks virus-size particles. 2020, Retrived from https://advance.qld.gov.au/whatshappening/stories-about-innovation/new-filter-material-blocks-virus-size-particles.

43. Francisco, S. Testing demonstrates Molekule's air purification technology inactivates H1N1 flu virus and Coronavirus strains, 2021, Retrieved from https://www.prnewswire.com/news-releases/testingdemonstrates-molekules-air-purification-technology-inactivates-h1n1-flu-virus-and-coronavirus-strains301208274.html.

44. Dimitra, C. Nano4-Hygiene Life | Elliminates H1n1-Sars Cov-Hiv-1, 2020, Retrived from https://www.nano4life.co/post/nano-4-hygiene-life-elliminates-sars-cov-h1n1-hiv-and-many-more.

45. FN Nano Inc, Titania-based Photocatalytic Nanocoating, First Line of Defense Against Coronavirus. Retrived from https://statnano.com/news/67556/Titania-based-Photocatalytic-Nanocoating-First-Line-ofDefense-Against-Coronavirus\#ixzz611xIM9PR.

46. TNN. Silver nanoparticles infused sanitizer on the anvil. Retrieved from http://timesofindia.indiatimes.com/articleshow/75089018.cms?utm_source=contentofinterest\&utm_mediu $\mathrm{m}=$ text\&utm_campaign=cppst

47. Ruinan, Z. HKUST develops antimicrobial coating against coronavirus. 2020, Retrived from https://www.chinadailyhk.com/article/124122.

48. Estefânia V. R.; Campos, E. V. R.; Pereira, A. E. S.; Oliveira, J. D.; Carvalho, L.B.; Casagrande, M. G.; Lima, R.; Fraceto, L. F. How can nanotechnology help to combat COVID-19? Opportunities and urgent nee. J Nanobiotechnology. 2020, 18, 125, 10.1186/s12951-020-00685-4.

49. Chapman, R.; Lin, Y.; Burnapp, M.; Bentham, A.; Hillier, D.; Zabron, A.; Khan, S.; Matthew Tyreman, M.; Stevens, M. S. Multivalent Nanoparticle Networks Enable Point of Care Detection of Human PhospholipaseA2 in Serum. ACS Nano 2015, 9, 3, 2565-2573, https://doi.org/10.1021/nn5057595

50. Searching for a Covid-19 Testing Breakthrough. 2020, Retrived from https://www.understandingnano.com/covid-19-diagonstics-nanotechnology.html.

51. Norway Turns Silica-coated Iron Oxide Nanoparticles into 150,000 COVID-19 Tests Per Week 2020, Retrieved from https://statnano.com/news/67573/Norway-Turns-Silica-coated-Iron-OxideNanoparticles-into-150-000-COVID-19-Tests-Per-Week\#ixzz6126iNzsU

52. Peptide therapies could disable coronavirus' spike proteins. 2020, https://news.northwestern.edu/stories/2020/04/peptide-therapies-could-disable-coronavirus-spike-proteins/

53. Northwestern. Nanostructures could safely deliver a notoriously fragile drug to coronavirus. 2020, https://phys.org/news/2020-04-nanostructures-safely-notoriously-fragile-drug.html. 
54. Chitosan nanoparticles suitable for aerosol treatment of covid-19 patients. 2020, Retrieved from https://www.ondrugdelivery.com/chitosan-nanoparticles-suitable-for-aerosol-treatment-of-covid-19patients/ 